\title{
Leading Multicultural Teams in the PR China
}

\section{Reinhard Meckl, Matthias Johanning}

Department of International Management, University of Bayreuth, Bayreuth, Germany.

Email: reinhard.meck1@uni-bayreuth.de, matthias.johanning@gmail.com

Received November $1^{\text {st }}, 2012$; revised December $2^{\text {nd }}, 2012$; accepted January $3^{\text {rd }}, 2013$

\begin{abstract}
This paper examines the effect of transformational, transactional and passive leadership on the performance of multicultural teams in the People's Republic (PR) of China. 42 multicultural teams with a total of 158 team members employed at German companies in the PR China completed a questionnaire which has been analyzed to show the extent to which these three leadership styles moderate the relationship between cultural diversity and social integration, satisfaction, communication effectiveness and conflict. To evince an explanation for discrepancies it has also been examined whether all three leadership styles justified mediating effects. The relationship between cultural diversity and several team variables has been explained through the resource-oriented theory, the information processing theory, the similarity-attraction theory and the social identity and social categorization theory. The effect of transformational, transactional and passive leadership is based on the theory of charismatic leadership from Bass and its related "Full Range of Leadership". Results suggest transformational, transactional and passive leadership moderate the relationship between cultural diversity and conflict. In addition, it has been shown that transactional leadership mediates all four group variables. This study identifies practical implications and proposes an agenda for future research.
\end{abstract}

Keywords: Culture; Diversity; Leadership; Transformational; Transactional; Multicultural Teams; China

\section{Introduction}

In the course of growing internationalization, multicultural teams have been established as standard in most multi-national companies [1]. This development is especially applicable to the PR China, whose status as the second biggest economy behind the USA reveals its importance for the business operations of international companies [2]. However, collaboration within multicultural teams in the PR China does not always proceed smoothly. Besides the clearly positive outcomes of multicultural teams such as advanced problem solving capabilities, negative effects might also occur. To ensure a constructive working environment, it is the task of the team leader to align all team members on overall procedures and to coordinate cooperation within the team. Because existing leadership instruments cannot necessarily be applied to varying culturally heterogeneous working environments, the different leadership situation of the PR China may cause difficulties and requires the selection of an appropriate leadership style. Henceforth the underlying problem of this study is being formulated as follows: through which specific leadership style can the performance of multicultural teams in the PR China be increased?

The relevance of this problem can be illustrated through three developments which run in parallel and impact the amplified use of teams to complete tasks: A greater organization of work in teams [3], a progressive internationalization of business activities [4] and an enhanced information and communication technology [5]. The conflation of these factors and the increasing importance of the PR China reflect the relevance of the underlying problem and can be summarized as follows: multicultural teams will play a key role in companies operating in the PR China, however the effect of cultural diversity in teams has not been entirely revealed yet. Based on the defined problem, this paper examines the effect of leadership styles on the performance of multicultural teams in the PR China. Specifically, this paper reveals to which extent transformational, transactional and passive leadership lead to greater performance of multicultural teams in the PR China. In a nutshell it can be stated that: the objective of this paper is to empirically examine the effect of transformational, transactional and passive leadership on the performance of multicultural teams in the PR China.

\section{Conceptual Framework}

\subsection{Multicultural Teams}

A team comprises two or more persons who in the course of their interaction, illustrate an intact, social system with 
a clear role structure and who undertake through direct, mutually dependent cooperation, one or more tasks within an organizational setting [6-9]. The success of a team can be measured to the extent it achieves the given target; therefore effectiveness serves as a starting point for successfully modeling a team. To explain the basic relationship between the different team variables, the Input-Mediator-Output (IMO) effectiveness model has been used, as it sufficiently describes the association of the different variables and underlines the importance of mediators as intermediate variables $[10,11]$. Based on this classification framework, the fundamental characteristic which impacts the different group variables and ultimately the overall performance of multicultural teams is cultural diversity as the input factor.

Cultural diversity is a multi-faceted construct and from a substantive view, can simply be described as variety in the different knowledge supplies of humans. Such knowledge is defined as cross-linked information in a certain context, which contains theoretical findings, practical advices and guidelines [12]. These knowledge supplies are based on value concepts, characterized through a dedicated structure, mentally accentuated, beyond individualistic, but dominant, dynamic, learnable, created by humans and able to be experienced on different layers and impact behavior [13-17]. The combination of these elements impact humans in their thinking and behavior, whereby their acceptance, performance, satisfaction and development in a team is being influenced [18]. From a spatial view, a cultural group can be assigned to a cultural area which is being classified by either surface-level aspects such as geographic, national or language affiliation or deep-level aspects such as sociological or humanistic affiliation $[16,19,20]$.

Previous research findings indicate that members of a cultural group can be part of multiple cultures, which can conflict with each other or from which their members can interchange (among different groups). In addition, not all members of a cultural group necessarily have to match in regard to each cultural attribute. Rather a significant cultural variability seems to exist within cultural groups [21]. Recent findings also point out that beyond cultures, new boundaries have been established and the stability of existing cultural boundaries has decreased [22,23]. These cultural influences seem to have a stronger intra-individual effect than commonly assumed today [21]. This means that individualistic and collectivistic knowledge structures need to be captured and the cultural context has to be kept in mind, should further research on culture be undertaken [21]. Correspondingly, cultural diversity as variety in the different knowledge supplies of humans is being captured through its underlying value orientations in this paper, which means individuals form a cultural group based on deep-level value attributes rather than surface-level aspects such as national affiliation. However country specific attributes have been regarded in this paper as framework to the empirical data gathering as well as development of hypotheses, as they form a key driver to establish value orientations.

\subsection{Effects of Cultural Diversity in Teams}

A first explanation for the effect of cultural diversity on the success of teams is given by the resource-oriented theory. It contains the basic assumption that all resources available to a company ultimately determine their competitiveness [24,25]. Culturally diverse team members contribute multiple abilities to a team, which leads to a team-specific core competence and has a positive impact on the team's performance as well as its ability to solve problems [26]. Another approach used to explain the positive effect of team cultural diversity on their success is reflected in the information processing theory. This theory substantiates the resource-oriented theory in regard to the information processing component and postulates that culturally diverse team members have to switch to an active information processing status, in order to be able to compare the different knowledge and action schemes with each other and to find a mutually agreed result. This leads to the establishment of a complex plot, through which the quality of group decisions increase [27-29].

In contrast to both of the above mentioned theories, the social identity and social categorization theory postulates an opposite effect of cultural diversity in teams. According to this theory, individuals try to picture themelves in a way which satisfies them in comparison to their related social environment [30,31]. This procedure of finding the right identity evolves from a self-categorization process, by which the social environment is classified following specific categories, which are then prioritized in regard to how similar they are in relation to someone's existing purposes and attitudes. Team members associate themselves with other team members who show a similar social identity, which leads to an interrupted interaction with different team members. However, there is also a chance for each individual to find a similar identity within the same team, whereupon the team as a whole can dissociate themselves from other teams. As a result the cooperation between different teams would be interrupted.

A similar argumentation is followed by the similarityattraction theory, which takes the basic assumption that individuals with comparable attributes share similar values and life experience, which henceforth leads to an increased inter-human attraction and mutual sympathy [32-34]. Correspondingly, culturally heterogeneous team members diverge in their knowledge supplies and values, which results in a decreasing similarity between the dif- 
ferent team members. This would mean different team members are less attractive in terms of interaction, only little sympathy is sensed for them and they generally keep distance from each other [35].

To better understand the effect of cultural diversity in teams, this paper uses a taxonomy from Stahl et al. [1], which serves as tool for classifying mediators based on whether they are associated with divergence or convergence [36] and whether they lead to process winnings or process losses [37]. Cultural diversity itself adds multifacet values, ideas and perspectives to a team, which influences the convergent and divergent processes in two ways [1]. Firstly, it is assumed that cultural diversity as an input factor reduces convergent processes, because the justification of a team to mutual objectives, ideas and approaches would be interrupted. This implies constructs such as communication, satisfaction or social integration evolve more weakly and that respectively, their positive effect on team performance reduces. In direct contrast, loss generating processes such as group thinking would also reduce, whereupon less process losses are suffered $[1,38]$. Secondly, it is assumed that cultural diversity as an input factor supports divergent processes, because multi-facet values and ideas are brought into a team and the varying patterns of the different team members increases. This means that cultural diversity in teams lead to higher creativity, which leads to a stronger generation of process profits. Nevertheless, more conflict might also occur, which would cause parallel process losses $[1,39]$.

\subsection{Review of Previous Empirical Findings}

Both the underlying taxonomy and different theories express an ambivalent effect of cultural diversity in teams. Such an ambivalent effect has also been demonstrated in existing empirical studies on the influence of cultural diversity on the overall team performance. First research analyzed the direct effect of cultural diversity on the performance of teams. As a result many studies demonstrated both negative $[40,41]$ and positive effects $[27,42]$ of cultural diversity on the performance of teams," which led some authors to call diversity research a double edged sword" [43]. Meta-Analyses support these findings. Bowers/Pharmer/Salas [44] and Webber/Donahue [45] could not find any direct relationship between diversity and performance; or in the case of Stewart [46], only a slight negative effect has been identified.

Corresponding to these findings, a subsequent research path put the basic assumption that some variables could act as mediators or moderators in a team [43]. Stahl et al. [1] present a summary of related findings in their metaanalysis of 108 empirical studies on processes and performance in 10,632 teams. Results related to the variables of satisfaction, social integration, effective communication and conflict have been taken over as basis for this paper (Figure 1). Creativity has not been explored further in this paper.

Conflict is characterized as "perceived incompatibilities or perceptions by the parties involved that they hold discrepant views or have interpersonal incompatibilities" [47] and are classified in types of task conflict, relationship conflict and process conflict [48]. Even though conflict can have constructive effects in teams [49], e.g. through enabling creativity [50] or supporting team development $[51,52]$, in a meta-analysis from De Dreu/ Weingart [53], rather a negative effect of all types of conflict has been identified. As a result, a low but significant positive correlation between cultural diversity and conflict has been found, which means that cultural diversity leads to more conflict [1].

Communication effectiveness reflects the degree to which information and meaning have been transferred to steer opinions, attitudes, expectations and behaviors of specific addressees according to specific objectives [54]. High communication effectiveness has a positive effect on the team performance [55-57]. With regards to the influence of cultural diversity on communication effectiveness, a non-significant (n.s.) effect has been revealed. This means the positive influence of communication effectiveness on the success of teams does not change at a higher degree of cultural diversity as the input factor [1]. Depending whether cultural diversity is measured on a deep-level or surface-level, a positive respectively negative effect has been revealed.

Opposite to the findings of Stahl et al., a couple of studies about diversity as input factor demonstrate that homogenous teams have a significant positive effect on communication and heterogeneous teams respectively must have a negative effect [44]. In addition, both the social identity/social categorization theory and similarityattraction theory indicate that cultural diversity should have a significant negative effect on communication effectiveness. As a result, this paper aligns with the underlying theoretical approach and assumes a negative effect of cultural diversity on communication effectiveness.

Satisfaction is conceived as a positive emotional condition, evolving from the evaluation of everybody's working space and the experiences absorbed at work [58].

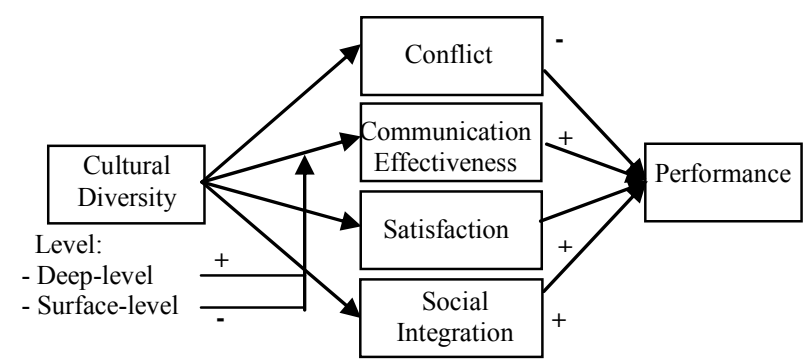

Figure 1. Findings on the effect of cultural diversity on team performance. 
Satisfaction in teams has been assessed positively throughout the literature on team research, even if only low correlations have been identified [59]. In the meta-analysis of Stahl et al. the effect of cultural diversity on satisfaction showed a significant positive effect [1].

Social integration on group level has been understood as a convergent, multi-faceted process which describes "the attraction to the group, satisfaction with other members of the group, and social interaction among the group members" [40]. This paper operationalizes social integration through group cohesion and social interaction, as satisfaction itself is captured as an independent construct. In a nutshell, the existence of social integration seems to lead to positive effects such as convergence and higher attraction [60-62], even though its positive effect on team effectiveness is contentious [63]. Taking a closer look at meta-analyses from Evans/Dion [64] and Mullen/Cooper [65], a positive relationship between social integration and cohesion and performance has been identified. With regard to the influence of cultural diversity on social integration, Stahl et al. detected a low, significant negative effect [1]. This finding is consistent with the underlying theories as well as most of the mentioned papers and is henceforth also assumed in this paper.

\section{Development of Hypotheses and Research Model}

Define Even though many mediators and moderators have been explored up to now, Stahl et al. point out further areas that research needs to pay attention to [1]. Besides a focus on additional mediators, a concentration on process-oriented moderators has been stressed, e.g. the leadership style of the team leader. In addition, further field research with large sample sizes should be conducted and closely examined, in order to reveal whether certain diversity attributes are more salient in some cultural contexts than in others. In this paper, these open research topics will be addressed by revealing the moderating effect of transformational, transactional and passive leadership in multicultural teams in the PR China.

Leadership can be described as the attempt of a person to influence the actions of other team members by their own means, in order to accomplish the defined targets of a company [66]. It has been stated in various research papers that concepts of leadership are strongly linked to cultural values [67,68]. Gelfand et al. [69] support this premise, as they identified that the relationship between transformational leadership and followers' attitude will be moderated by the cultural context. Specifically applicable to Chinese culture, it has been revealed the way a leader is perceived from Chinese people is different from Western standard and therefore impacts the selection of an appropriate leadership style [70].

In this paper, leadership is based on the theory of transformational leadership from Bass, according to which the guided team members should develop a stronger selfmotivation arising from an extraordinary charisma of the team leader [71,72]. Similar to other charismatic leadership theories, the approach of Bass is of utmost interest at its linkage to international management, as it should especially give support in transition times and achieve outstanding performance within the framework of increasing globalization and rising competition [73]. Such a situation of an economy undergoing a transitional shift can especially be found in China, where it can be assumed that transformational leadership has an exceptional effect within teams there. Besides transformational leadership, another major component of Bass' theory is the related transactional leadership style. Some studies also include a third component called "passive leadership", which altogether form the "Full Range of Leadership" [74]. All three leadership styles form the basis for developing the underlying hypotheses which will be described more detailed in the following paragraphs [75]. The typology of Bass has been tested in different cultural settings and has shown first evidence that varying cultural settings lead to a different perception of transformational leadership [73, 76]. In Asia collectivism and power distance seem to moderate the importance of leadership [77], while specifically for the Chinese culture a higher correlation between transformational leadership and commitment has been revealed in comparison to German culture [78].

Following Bass, transformational leadership is being defined as an extension respectively supplement to transactional leadership and characterized by "not merely recognizing associates' needs, but by attempting to develop those needs from lower to higher levels of maturity. Transformational leaders engage the full person so that associates are developed into leaders" [79]. Instead of a merely rational exchange principle, an emotional or motivational component has been ushered in and the team leader as role model has been brought to the center [80]. To achieve such outcomes, the team leader needs to be in line with the four components of transformational leadership and accordingly, to stimulate their team members intellectually, to serve as a role model, to impart attractive visions and to satisfy their personal needs $[72,81]$.

With regard to the proposed moderating effect, it is assumed that transformational leadership has an influence on the dependent variables in teams in the PR China, with a positive effect on the team performance. This means the positive correlation between cultural diversity and conflict reduces, but contrarily increases between cultural diversity and both communication effectiveness and satisfaction. The negative correlation between cultural diversity and social integration would be reduced. An overview on the different hypotheses can be found in Figure 2. 
Hypothesis 1: If teams in the PR China are led transformational, this leadership style moderates the relationship between cultural diversity and the intervening variables to the extent of increasing performance.

Hypothesis $1 a$ : If teams in the PR China are led transformational, this leadership style weakens the positive relationship between cultural diversity and the existence of conflict.

Hypothesis $1 b$ : If teams in the PR China are led transformational, this leadership style weakens the negative relationship between cultural diversity and the existence of communication effectiveness.

Hypothesis $1 c$ : If teams in the PR China are led transformational, this leadership style supports the positive relationship between cultural diversity and the existence of satisfaction.

Hypothesis $1 d$ : If teams in the PR China are led transformational, this leadership style weakens the negative relationship between cultural diversity and the existence of social integration.

Transactional leadership ensures that the concerns of the different team members are included in the overall working process and will be fulfilled through dedicated exchange processes $[80,82]$. One example for such processes is the exchange of salary for work performance. The appeals and concerns of the team members are to be considered to the extent to which they seem to be useful for target achievement. Transactional leadership consequently bases itself on the concept of a rational, calculating "homo economicus", who thrives to fulfill its own necessities within a clearly defined framework $[72,83]$. As components of transactional leadership, Bass/Avolio defined constructive exchange processes and corrective leadership elements, which have also been declared as "contingent reward" respectively "active management by exception" [79].

It is assumed that such leadership style leads to greater performance of teams in the PR China, as it embeds the interests of the different group members', actively manages them and provides a clearly defined incentive structure which lead to higher motivation and dedication.

This specifically accounts for the Chinese market as the average per capita income is still relatively low and Confucian virtues of loyalty and reliability towards superiors mould each group member being in line with transactional leadership principles.

However the effect of transactional leadership is assumed to be less intense than for transformational leadership, because visionary components are missing which appear to be the main drivers of higher motivation in the concept of transformational leadership.

This means that the positive correlation between cultural diversity and conflict would be reduced, but for communication effectiveness and satisfaction, increased. Likewise, the negative correlation between cultural diversity and social integration would reduce, however showing a weaker total effect than for transformational leadership.

Hypothesis 2: If teams in the PR China are led transactional, this leadership style moderates the relationship between cultural diversity and the intervening variables to the extent of increasing performance but less intense than for transformational leadership.

Hypothesis $2 a$ : If teams in the PR China are led transactional, this leadership style weakens the positive relationship between cultural diversity and the existence of conflict but less intense than for transformational leadership.

Hypothesis $2 b$ : If teams in the PR China are led transactional, this leadership style weakens the negative relationship between cultural diversity and the existence of communication effectiveness but less intense than for transformational leadership.

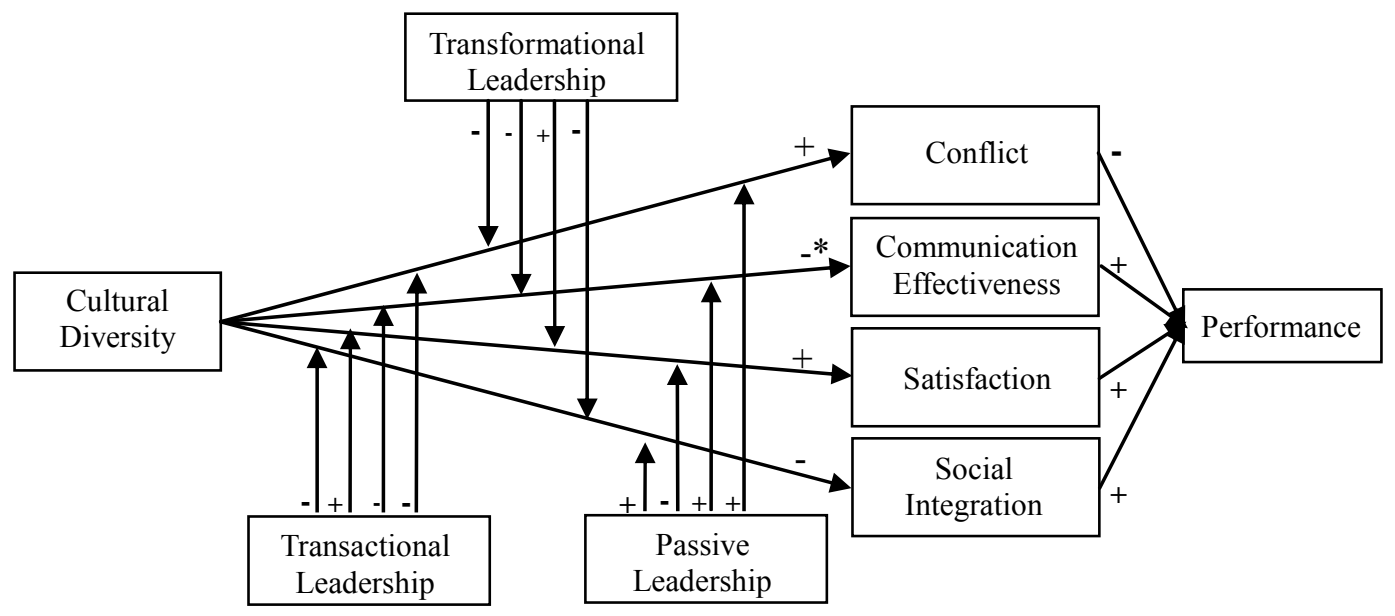

Figure 2. Research model. *In accordance with the underlying theories a significant negative relationship is assumed in this paper. 
Hypothesis 2c: If teams in the PR China are led transactional, this leadership style supports the positive relationship between cultural diversity and the existence of satisfaction but less intense than for transformational leadership.

Hypothesis $2 d$ : If teams in the PR China are led transactional, this leadership style weakens the negative relationship between cultural diversity and the existence of social integration but less intense than for transformational leadership.

Contrarily to transformational and transactional leaders, a passive leader avoids an effective and active leadership behavior and barely influences team processes. Bass/Avolio calls this kind of leadership "non-leadership" [84] and summarize its components as "passive management by exception" and "laissez-faire leadership" [85]. In accordance with both components, it is assumed that passive leadership in teams in the PR China has a negative effect on team performance as it is characterized by an ineffective and inactive leadership behavior, lacks visionary respectively motivational elements and does not offer opportunities to correct or steer group processes. This specifically accounts for the Chinese market where Confucian ideas of a strong hierarchy seem to not comply with the concept of passive leadership. This means the positive correlation between cultural diversity and conflict would increase, but decrease for communication effectiveness and satisfaction. The negative correlation between cultural diversity and social integration would further increase.

Hypothesis 3: If teams in the PR China are led passive, this leadership style moderates the relationship between cultural diversity and the intervening variables to the extent of decreasing performance.

Hypothesis $3 a$ : If teams in the PR China are led passive, this leadership style supports the positive relationship between cultural diversity and the existence of conflict.

Hypothesis $3 b$ : If teams in the PR China are led passive, this leadership style supports the negative relationship between cultural diversity and the existence of communication effectiveness.

Hypothesis $3 c$ : If teams in the PR China are led passive, this leadership style weakens the positive relationship between cultural diversity and the existence of satisfaction.

Hypothesis $3 d$ : If teams in the PR China are led passive, this leadership style supports the negative relationship between cultural diversity and the existence of social integration.

\section{Method}

\subsection{Sample and Data Collection}

To test the hypotheses, 42 multicultural teams of German companies in the PR China have been questioned, with a total of 158 team members. The survey has been conducted using a web-based questionnaire, which was presented in both English and Chinese and completed by both the team leader and team members. The questionnaire consisted of four main components, which have been placed between an introduction and closing word. After general characteristics of the group and its members have been inquired, further questions on group processes, cultural value orientations and leadership styles have been raised. Summarizing these components a clear characteristic of each item on individual level was captured. The questionnaire has been reviewed in a pretest including six Chinese, two Australians and six Germans, who altogether previously were, or still are engaged in a team within a German company in the PR China. The survey was running from June to November 2010 and focused on two groups which have been approached and processed differently.

Focus group 1: A German automobile company which is active in the Chinese market has been chosen as the main focus of this survey. All of its 721 employees received an invitation via email with the request to participate in the survey. In the invitation the purpose of the questionnaire was explained and each employee was asked to complete the web-based questionnaire within four weeks.

Focus group 2: To increase the sample size, an additional 200 companies have been chosen from the German Company Directory owned by the German Chamber of Commerce in Shanghai and appealed to complete the questionnaire within two weeks. The invitation contained information on the underlying idea and purpose of the survey and each recipient has been asked to distribute the subsequent link within the company. Five companies requested further information or informed us that they had forwarded the questionnaire to colleagues within their company, who were then additionally updated on the goals and purpose of the questionnaire.

As a result, 201 companies have been contacted with a total of 921 executive contacts (721 employees of the German automotive company and 200 individuals from different companies in the PR China). The number of forwarded invitations is uncertain, thus the final number of addressed teams is under speculation. Coming from 921 conveyed invitations, 497 persons opened the link, whereof 313 started the questionnaire or completely finished it. $50.4 \%$ of the original 313 data records have been eliminated within the data cleansing; therefore $158 \mathrm{com}$ plete data records have been available for the ongoing investigation, through which the final sample size was created. The response rate can be determined at $17.2 \%$.

Out of the 42 teams, a total of 33 teams have been assigned to the first focus group, the remaining nine teams 
(and corresponding 33 team members) can be allocated to ten additional German companies in the PR China. With regard to the team size, six groups with two members, 14 groups with three and four members, three groups with five and seven members as well as two groups with six team members have been identified after data collection. This means around half of all collected teams consisted of three or less members and with $67 \%$ of all teams the groups with three or four members build the majority.

A total of 17 teams consisted of Chinese members only, while all remaining teams have been divers in terms of national affiliation. Please note in this paper the inclusion of 17 teams with solely Chinese members does not interfere with the idea of multiculturalism, as culture has been defined by values instead of nationality. Taking the data on the abovementioned 42 teams into account, an average of $29 \%$ of all members per team participated in the survey. This means most teams have been represented partially only. Each team has been represented by a team leader, where of 21 team leaders were German, 20 of them Chinese and the remaining team leader Indian. Each team leader has been collocated with its team members.

The team members have been around 33 years in average, 74 of them male and 78 female. They covered all major functions of the supply chain, demonstrated a team tenure of on average 30 months and an average education length of 16.9 years. Therefore the sample demonstrated good representation in regard to their gender and functional allocation. However the result might imply a branch bias, as $86.7 \%$ of all participants are assigned to the automotive branch. In addition, a characteristic sign was that mainly younger teams from middle and lower management participated in the survey.

\subsection{Measures}

Cultural diversity: to measure cultural value orientations, the scales of the "Cultural Perspectives Questionaire (CPQ)" from Maznevski et al. [86] have been taken, capturing cultural variations based on the theory of Kluckhohn/Strodtbeck [87]. In this paper, a German version of the CPQ from Bachmann/Wolf [88] has been used, which explicitly fathoms the effects of cultural diversity on company level and therefore should be applied within organizations [89]. The original questionnaire consists of 96 single-sentence statements, but has been reduced to 59 items in this paper due to its length and the redundancy of many questions. The eliminated items have been allocated in a well-balanced manner to all relevant scales. To capture the five variations of humannature-orientation, human-environment-orientation, time orientation, activity orientation and relational orientation, a seven-stage response format has been selected with the extreme characteristics " 1 = fully disagree" to " 7 = fully agree". To capture cultural diversity, the Euklid Distance measure has been used. Firstly the Euklid distance for each sub-category of a value orientation has been calculated on individual level and the gap to each team member identified. The different distance measures have been averaged over the different team members and summarized on group level. Secondly these distance measures on group level have been summarized for each sub-value category and averaged over the five cultural value orientations, which resulted in one measure for cultural diversity on team level.

Based on these explanation is can be assumed that within a team, its members differ from another in their position along each cultural value orientation. That means in this paper diversity is consistent with the idea of diversity as separation, which considers diversity as "composition of differences in (lateral) position or opinion among unit members, primarily of value, belief or attitude; disagreement of opposition" [90].

Conflict: All three conflict variables have been captured through the "Intragroup conflict scale" from Jehn [47,52] and Jehn/Shah [91]. Task conflict has been measured with three items, whereof one item has been eliminated [47,52]. Relationship conflict has been captured by four items $[47,52,92]$ and process conflict by three items [91].

Communication effectiveness: The items capturing communication effectiveness in teams have been taken from Earley/Mosakowski [93] and contain two items on a 7point Likert scale. They are "team-members have open and honest communication during work" and "team-members really listen to one another and seem to understand each other's feelings and points of view".

Social integration: To capture social integration as a uniform construct rather than through its sub-constructs, eight items have been taken from Smith et al. [61] on a 5-point Likert scale. Within this variable, four items capture social interactions, whereof one item has been eliminated. In addition, two items have been polarized in reverse order which means their underlying statements have been phrased negatively. The remaining four items served to capture group cohesion, which Smith et al. again took from Seashore [94].

Satisfaction: Satisfaction has been measured in relation to social interactions and the overall team performance. The measurement of satisfaction with social interactions is based on a 2-item scale from van der Vegt/ Emans [95]. This scale has been supplemented with an item to capture the satisfaction with the supervisor. The measurement of satisfaction with the overall team performance is based on a 2-item scale which has been taken from Earley/Mosakowski [93]. One item has been polarized in reverse order. 
Transformational, transactional and passive leadership: To capture the "Full Range of Leadership" and especially its major element of transformational leadership the "Multifactor Leadership Questionnaire (MLQ)" from Bass/Avolio has been used [79]. A study of Vandenberghe/Stordeur/D'hoore [96] confirmed the factor structure of the MLQ expresses all components of transformational leadership. It reveals the existence of transformational, transactional and passive leadership through originally 91 items. All items have been retrieved on a 5-point Likert scale with the extreme attributes $1=$ "Not at all" and $5=$ "Frequently, if not always". However, 14 items designed to capture effectiveness have been eliminated from the original questionnaire, as they are not of relevance for the present study. In addition, four items capturing satisfaction have been excluded, as satisfaction exists as an independent construct in this paper. The remaining 73 items constantly concerned both the team leader and team members, therefore the first 36 items have been classified respectively according to the respondents' dedicated role: depending on the addressee, the statement applied to the team leader or the team member only, which enables us to combine two items in one statement. In advance of the different items concerning leadership styles, this has been checked through one item, whether the participant previously occupied the role of a team leader or not.

Performance: From economic perspective and a general standpoint performance can be described as the degree to which targets have been achieved. In this paper performance is not measured directly and therefore will not be described further.

\subsection{Data Analysis}

For the analysis of the path diagram, the structural equation modeling (SEM) technique has been used, based on a PLS-estimation. The calculation itself has been conducted with the software smartPLS and moderating effects have been proven through the creation of interaction terms. The adequate significance level has been determined at a $\alpha$-value of $5 \%$, with a corresponding tvalue of 1.684. A power analysis using the software GPOWER revealed, that an existing relationship between two variables with the given data set is proven right, with a probability of $84.43 \%$ for one-tailed, respectively $78.35 \%$ for two-tailed tests.

Before starting with the underlying analysis of the SEM, the reliability on item level has been controlled to check whether the quality of the scales is sufficient. Items with insufficient accuracy of measurement have been eliminated. To evaluate the reliability, Cronbachs Alpha has been captured using the software SPSS 15.0. Due to critical results the variables concerning satisfaction with the team performance (Cronbachs Alpha:
-1.603), time orientation (Cronbachs Alpha $<0.432$ for all scales) and human-nature-orientation (Cronbachs Alpha $<0.380$ for all scales) have been eliminated. In addition, a total of seven items with a Cronbachs Alpha $<0.6$ have been deleted, well-balanced between the different scales.

The overall assessment of the SEM was based on a cumulative evaluation of related quality factors, from both the formative and reflective measurement models. For the reflective measurement model, four validity and reliability subtypes have been examined, the content validity, indicator reliability, construct reliability and discriminant validity. For the formative measurement model, the expert validity, indicator relevance and multicollinearity have been examined [97]. On the specific level of the SEM, the effect size $\mathrm{f}^{2}$, relevance of prognosis $\mathrm{Q}^{2}$, coefficient of determination $\mathrm{R}^{2}$ and a path assessment have been considered. All objectivity criteria concerning the realization, evaluation and interpretation have been abided.

\section{Results}

\subsection{Moderating and Mediation Effects}

All moderating effects of transformational, transactional and passive leadership on the relationship between cultural diversity and social integration, communication effectiveness or satisfaction in teams of German companies in the PR China revealed t-values $<1.684$ and therefore have not been declared significant (Figure 3). As a result, the hypotheses H1b-H3d have been declined. Rather a positive, significant moderating effect for all three leadership styles has been identified for the relationship between cultural diversity and conflict in teams of German companies in the PR China. The moderating effect of transformational leadership has not been substantially higher compared to transactional leadership, therefore hypotheses H1a and H3a could be confirmed, while hypothesis $\mathrm{H} 2 \mathrm{a}$ has been rejected. All moderating effects demonstrated low effect sizes and have been accordingly weak (Table 1).

Even though no hypotheses have been formulated to investigate a potential mediating effect, we explored the relationship as a matter of interest and to better understand the current results. It has been revealed that transactional leadership mediated the effect of cultural diversity on all four group variables in teams of German companies in the PR China. Transactional leadership therefore further explained the relationship between both variables; the related VAF values (Variance Account for) indicated a definite mediating effect. For transformational and passive leadership, no significant mediating effect could be revealed due to a $z$-value $<1.684$ (Table 1). 


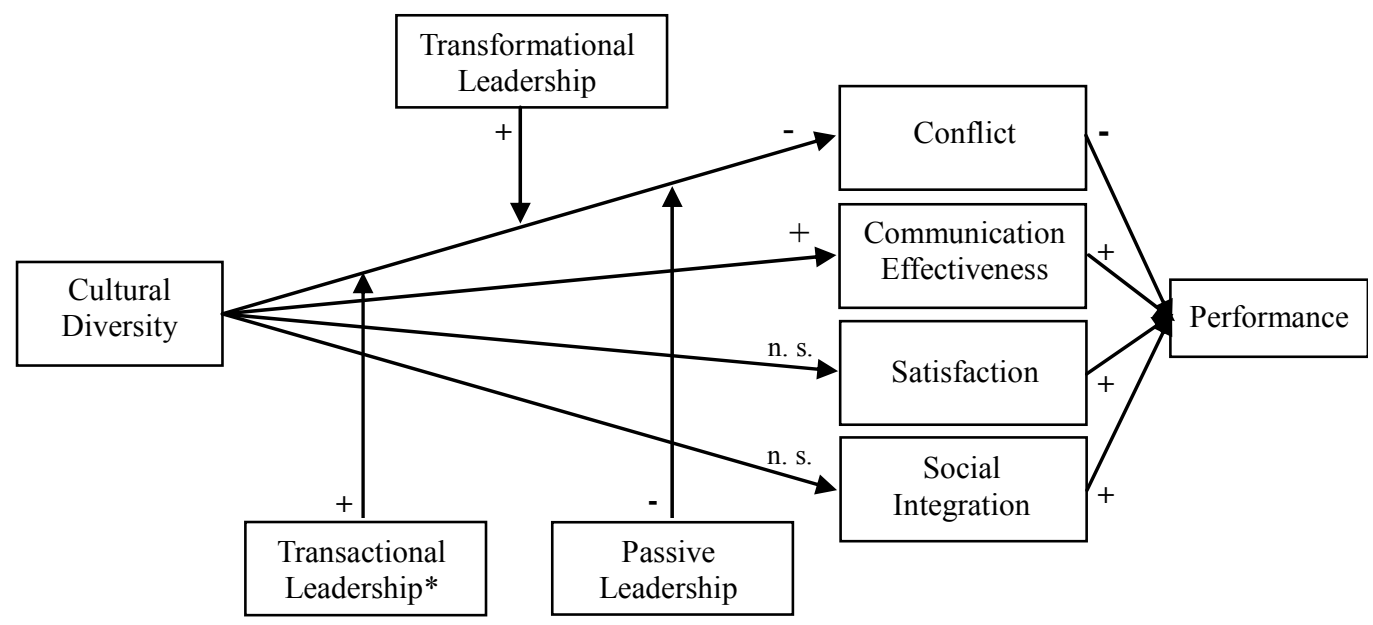

Figure 3. Research model. * Additionally for transactional leadership a mediating effect has been identified with the following attributes: Conflict (negative), communication effectiveness (positive), satisfaction (positive) and social integration (positive), n. $\mathbf{s .}=$ not significant.

Table 1. Results of the moderator and mediator analyses.

\begin{tabular}{|c|c|c|c|c|c|c|c|}
\hline & & \multicolumn{3}{|c|}{ Moderator Analysis } & \multicolumn{3}{|c|}{ Mediator Analysis } \\
\hline & $\begin{array}{l}\text { Path Coefficient } \\
\text { Basic Model }\end{array}$ & $\begin{array}{l}\text { Path Coefficient } \\
\text { Product term }\end{array}$ & T-Statistic & $\mathrm{f}^{2}$ & $\begin{array}{l}\text { Path Coefficient with } \\
\text { Mediator }\end{array}$ & Z-Statistic & VAF \\
\hline $\mathrm{CD}-\mathrm{SI}$ & $\begin{array}{c}0.172 \\
(\mathrm{t}=1.303)\end{array}$ & \multicolumn{3}{|c|}{$\begin{array}{l}\text { Has not been calculated due to a non-significant path coefficient } \\
\text { in the basic model }\end{array}$} & $\begin{array}{c}-0.006(\mathrm{TR}) \\
-0.083(\mathrm{TA}) \\
0.045(\mathrm{PL})\end{array}$ & $\begin{array}{l}1.568(\mathrm{TR}) \\
2.094(\mathrm{TA}) \\
1.289(\mathrm{PL})\end{array}$ & $\begin{array}{l}0.966 \text { (TR) } \\
1.475 \text { (TA) } \\
0.739 \text { (PL) }\end{array}$ \\
\hline $\mathrm{CD}-\mathrm{CE}$ & $0.325(t=2.376)$ & $\begin{array}{l}-0.001(\mathrm{TR}) \\
-0.150(\mathrm{TA}) \\
0.103(\mathrm{PL})\end{array}$ & $\begin{array}{l}0.014 \text { (TR) } \\
1.435 \text { (TA) } \\
0.976 \text { (PL) }\end{array}$ & $\begin{array}{c}0.0001 \text { (TR) } \\
0.0483(\mathrm{TA}) \\
-0.0168(\mathrm{PL})\end{array}$ & $\begin{array}{l}0.179 \text { (TR) } \\
0.089 \text { (TA) } \\
0.210 \text { (PL) }\end{array}$ & $\begin{array}{l}1.549 \text { (TR) } \\
2.100 \text { (TA) } \\
1.283 \text { (PL) }\end{array}$ & $\begin{array}{l}0.446 \text { (TR) } \\
0.722 \text { (TA) } \\
0.354 \text { (PL) }\end{array}$ \\
\hline $\mathrm{CD}-\mathrm{S}$ & $0.207(\mathrm{t}=1.515)$ & \multicolumn{3}{|c|}{$\begin{array}{l}\text { Has not been calculated due to a non-significant path coefficient } \\
\text { in the basic model }\end{array}$} & $\begin{array}{c}0.028(\mathrm{TR}) \\
-0.040(\mathrm{TA}) \\
0.077(\mathrm{PL})\end{array}$ & $\begin{array}{l}1.577 \text { (TR) } \\
2.082(\mathrm{TA}) \\
1.294(\mathrm{PL})\end{array}$ & $\begin{array}{l}0.862 \text { (TR) } \\
1.208 \text { (TA) } \\
0.629 \text { (PL) }\end{array}$ \\
\hline $\mathrm{CD}-\mathrm{C}$ & $-0.310(t=2.676)$ & $\begin{array}{r}0.174(\mathrm{TR}) \\
0.222(\mathrm{TA}) \\
-0.239(\mathrm{PL})\end{array}$ & $\begin{array}{l}1.862(\mathrm{TR}) \\
1.963(\mathrm{TA}) \\
2.033(\mathrm{PL})\end{array}$ & $\begin{array}{c}0.0627 \text { (TR) } \\
0.0899 \text { (TA) } \\
-0.1027 \text { (PL) }\end{array}$ & $\begin{array}{l}-0.166 \text { (TR) } \\
-0.095 \text { (TA) } \\
-0.174 \text { (PL) }\end{array}$ & $\begin{array}{l}-1.535 \text { (TR) } \\
-2.031 \text { (TA) } \\
-1.295 \text { (PL) }\end{array}$ & $\begin{array}{l}0.464 \text { (TR) } \\
0.696 \text { (TA) } \\
0.431 \text { (PL) }\end{array}$ \\
\hline
\end{tabular}

Abbreviations: CD: Cultural Diversity; SI: Social Integration; CE: Communication Effectiveness; S: Satisfaction; C: Conflict; VAF: Variance Account for; TR: Transformational Leadership; TA: Transactional Leadership; PL: Passive Leadership.

As one holistic result, it has been identified that cultural diversity exerts a supporting effect on communication effectiveness and further reduces conflict. Therefore cultural diversity generally seems to have a fundamental effect on the different team variables, with a positive effect on team performance. Figure 3 shows an overview of the results.

\subsection{Quality of the Different Measurement Models}

To interpret the quality of both the moderating and mediating results, firstly the inter-rater agreement on group level has been assessed using the "multi-item index of inter-rater agreement" $\left(\mathrm{r}_{\mathrm{wg}(\mathrm{j})}\right)$ of James, Demaree and Wolf $[98,99]$. As a result $86.4 \%$ of all $r_{w g(j)}$ indices crossed the threshold of 0.7 , which is still beyond the critical percentage of $85 \%$ [100]. This means the different group members match in their perception regarding a certain group attribute [100]. Secondly the quality of the measurement model and the underlying SEM has been assessed.

The four reflective measurement models of social integration, communication effectiveness, satisfaction and conflict revealed good validity and reliability, which means stable constructs can be assumed (Table 2). More specifically, the factor loadings as an indicator of the indicator reliability, show values in between 0.916 and one, which leads to the conclusion that the related indicators significantly contribute to explain the latent variables. In addition, the average variance extracted (AVE) has been bigger or at least equivalent to the squared correlations with the remaining factors, meaning that the Fornell-Larcker criteria as indicator for the discriminant validity has been fulfilled for all variables.

The formative construct of cultural diversity also demonstrated values of acceptable quality; however the stability of these results has been reduced due to the decreased complexity of cultural diversity and its weak 
indicator weights (Table 2). The variance inflation factor (VIF) showed values between one and 1.6 for all indicators, which means the top threshold value of ten has not been crossed. Additionally, the same procedure has been conducted for each sub-indicator to examine their multicollinearity. Rather good to very good VIF values have been revealed for the different sub-indicators, which leads to the conclusion that multicollinearity is not critical to cultural diversity.

The criteria to assess transformational, transactional and passive leadership revealed stable results; however the indicator weights indicated a varying quality to explain the different sub-variables. Nevertheless, stable results have been revealed overall. All VIF values of the different indicators are pointed between 3.3 and 6.3 for transformational leadership and at one for transactional and passive leadership. They clearly dropped below the threshold of a critical multicollinearity.

Within the basic model (Figure 3 excluding the mediators), a significant relationship between cultural diversity and communication effectiveness as well as con-

Table 2. Quality of the measurement model.

\begin{tabular}{|c|c|c|c|c|c|c|}
\hline & $\mathrm{CA} / \mathrm{AVE} / \mathrm{CR}$ & $\begin{array}{l}\text { Cultural } \\
\text { Diversity }\end{array}$ & TR & TA & PL & T-Value \\
\hline $\begin{array}{l}\text { Communication } \\
\text { Effectiveness }\end{array}$ & $1 / 1 / 1$ & & & & & \\
\hline Conflict & $0.93 / 0.88 / 0.96$ & & & & & \\
\hline \multicolumn{7}{|c|}{ Social Integration $0.92 / 0.92 / 0.96$} \\
\hline Satisfaction & $1 / 1 / 1$ & & & & & \\
\hline $\begin{array}{l}\text { Activity } \\
\text { Orientation }\end{array}$ & & -1.576 & & & & 1.697 \\
\hline $\begin{array}{l}\text { Human- } \\
\text { Environment- } \\
\text { Orientation }\end{array}$ & & 0.613 & & & & 0.526 \\
\hline $\begin{array}{l}\text { Relational } \\
\text { Orientation }\end{array}$ & & 3.413 & & & & 3.500 \\
\hline $\begin{array}{l}\text { Idealized } \\
\text { Influence }\end{array}$ & & & 0.508 & & & 1.022 \\
\hline $\begin{array}{c}\text { Individual } \\
\text { Consideration }\end{array}$ & & & 0.496 & & & 1.308 \\
\hline $\begin{array}{l}\text { Inspirational } \\
\text { Motivation }\end{array}$ & & & 0.969 & & & 1.809 \\
\hline $\begin{array}{l}\text { Intellectual } \\
\text { Stimulation }\end{array}$ & & & -0.105 & & & 0.216 \\
\hline $\begin{array}{l}\text { Contingent } \\
\text { Reward }\end{array}$ & & & & 1.928 & & 6.889 \\
\hline AMBE & & & & -0.962 & & 3.153 \\
\hline PMBE & & & & & 0.349 & 0.645 \\
\hline Laissez-Faire & & & & & 1.550 & 2.872 \\
\hline
\end{tabular}

Abbreviations: AMBE: Active Management by Exception; PMBE: Passive Management by Exception; CA: Cronbachs Alpha; AVE: Average Variance Extracted; CR: Composite Reliability; TR: Transformational Leadership; TA: Transactional Leadership; PL: Passive Leadership. flict have been indicated, however its relationship to social integration and satisfaction did not reveal any significant path coefficient. Moreover, the significant values came along with low coefficients of determination $\mathrm{R}^{2}$ and path coefficients. Communication effectiveness demonstrated a $R^{2}$ of 0.105 , conflict a slightly smaller $R^{2}$ of 0.096. Just a few percentage of the overall variance of the different team variables has been explained through cultural diversity [101]. The Stone-Geisser-Criteria $\mathrm{Q}^{2}$ indicated a value of 0.019 for communication effectiveness which means the model was not suited to reconstruct empirical data [102]. Conducting an evaluation of the entire SEM revealed that in general, a significant influence of cultural diversity on communication effectiveness and conflict existed, but had only a weak effect.

\section{Discussion and Conclusions}

After evaluating the resulting model it has been elucidated that it deviates from fundamental theoretical findings and assumptions being included in the entry model. For one thing, transformational, transactional and passive leadership seem to be significant and in line with the theoretical underpinnings for conflict only rather than for all team variables. However, both transformational and transactional leadership have a direct influence on the team variables, which is in accordance with the theoretical assumptions and basically has a positive effect on team performance. Contrarily, the direct effect of passive leadership on team performance is negative. Furthermore, cultural diversity seems not to have an ambivalent effect on the team variables, but contrary to assumptions, rather a consistently positive effect on team performance. Despite the deviation from the entry model and the theoretical underpinnings, the resulting model seemed to be intrinsically consistent, reasonable and was based on constructs with sufficient quality. Therefore the results can be principally used and additionally contain further information on how to reveal the influence of leadership and cultural diversity in teams in the PR China.

Firstly, the results indicate that transformational, transactional and passive leadership have a significant and positive influence on team performance for conflict only, whereof the effect of transactional leadership is not substantially stronger than for transformational leadership. This is evidence that leadership seems to be one component of relevance to reducing conflict, without having any influence on the remaining team variables. Secondly, transactional leadership seems to mediate the interaction between cultural diversity and the different team variables, and therefore delivers an explanation for its relationship. Thirdly, cultural diversity, considering its deeplevel aspects, is related to communication effectiveness and conflict with a positive influence on the overall team performance. This finding opposes the assumed ambiva- 
lent influence of cultural diversity in teams in the PR China and henceforth should be further stressed in future research. With this finding, the pending research question to reveal the effect of process-oriented moderators such as leadership style in teams has been addressed.

\section{Limitations}

Even though the resulting model has been analyzed using the latest methodology, including state of the art findings from the cultural field of research and being theoretically sound, the findings still have to be qualified. From a methodological perspective, collectivistic-based knowledge schemes related to cultural diversity are being integrated through a qualitative description of the Chinese national culture only. Furthermore, the overall construct of cultural diversity shows low values of validity, along with eliminated scales of time orientation and humannature-orientation. To be able to conduct the survey, the original questionnaire has been reduced by 37 items, which means there is a deviation to existing papers using the CPQ. A more basic restriction was given through the taken research model from Stahl et al. [1]. While our research model included four intervening variables only, in reality further variables such as creativity or group thinking might exist that could influence the performance of multicultural teams in the PR China. Finally, for some cases more members belonged to a team than participated in the survey. This means the data collection partially formed rather a limited picture of the overall team opinion and therefore might be slightly biased in comparison to the existing team.

From a substantive perspective, it can be concluded that the data analysis only affected teams of German companies in the PR China. This implicates on the one hand, that the data set is characterized through nation-specific cultural knowledge schemes, specifically the Chinese and German national cultures. On the other hand, all data is molded through a specific company culture. 33 of the total 42 teams are employed in a German automotive company, meaning the culture of this specific company is a striking attribute for a potential influence. Additionally, a majority of the respondents are associated with the automotive industry, which endangers the existence of a potential branch bias. Further, the data set only applies to the Chinese culture and especially has been extracted from the East coast of the PR China. As a result, the findings can be expanded to further cultures with the provision of the existing data set only and rather serve as evidence that similar relationships might apply to other cultures.

\section{Practical Implications}

The significant moderating effect of transformational and transactional leadership with its positive influence on overall team performance demonstrates that team leaders should apply both leadership styles to reduce conflict in multicultural teams in the PR China. On top of this conclusion, both leadership styles should be supported in the long run, as they have a direct positive effect on the team variables. Due to its mediating influence, transactional leadership plays an essential part in explaining the influence of cultural diversity on the team variables and again, on overall team performance. In practice it should be ensured that each leader develops an understanding of cultural diversity and its underlying value orientations. This is of particular relevance for the PR China, as the Chinese culture is highly dynamic and therefore might have a strong influence on the leadership acceptance of the different team members. Lastly, cultural diversity should be promoted in a team setting, as it has an influence on communication effectiveness and conflict with a positive effect on overall team performance. The positive effect of value-based cultural diversity has revealed that team composition should not be decided by country of origin, but based on value orientations as this might lead to greater team performance. Furthermore, this finding has severe consequences for the recruitment of new colleagues. Instead of simply observing and classifying employees by their different nationality, rather deep-level knowledge structures and cultural dimensions of the (potential) employees should be considered. Only a team composed in such a way enables the power of cultural diversity to show a positive influence on the overall team performance, especially in a culture in transition as given in the PR China.

\section{Future Research Agenda}

The findings indicate new approaches on how to further develop the underlying research model and stresses areas which future research should focus on. Firstly, cultural diversity seems to have a purely positive effect on the overall team performance in the PR China. This finding needs to be further analyzed taking other countries into account and especially highlighting positive rather than negative effects in teams. A first example is given by Stahl et al. [103], who explored the positive aspects of cross-cultural dynamics in teams from a more positive opportunities-focused perspective rather than a dominant negative problem-focused one. Secondly, the theoretical framework of cultural diversity has to be elaborated further, specifically referring to the development of a uniform understanding of the concept of cultural diversity and a more concrete way to reveal the influence of cultural diversity in teams. Based on this theoretical framework, the taxonomy for explaining the influence of cultural diversity in teams needs to be expanded. On the one 
hand, embedded variables must be included; on the other hand, moderating effects must also be integrated. By analogy with the expansion of the taxonomy for cultural diversity, the effect of leadership in multicultural teams should also be captured taxonomically. One tangible research question would be whether leadership in multicultural teams in the PR China only affects variables with a negative effect on the team performance or also variables with a positive effect on the team performance. Thirdly, further research should be the examination of additional mediators and moderators and their explicit interaction scheme with transformational, transactional and passive leadership. For instance one point of concentration might be the variables of group think or creativity. Finally, it is also still to be examined, to what degree a combination of moderators might influence the team composition. This would be in accordance with the request from Stahl et al. [1] to combine different variables.

\section{Acknowledgements}

This publication was funded by the German Research Foundation (DFG) and the University of Bayreuth in the funding program Open Access Publishing. Financial support is gratefully acknowledged.

\section{REFERENCES}

[1] G. K. Stahl, M. L. Maznevski, A. Voigt and K. Jonsen, "Unraveling the Effects of Cultural Diversity in Teams: A Meta-Analysis of Research on Multicultural Work Groups," Journal of International Business Studies, Vol. 20, No. 1, 2009, pp. 1-20.

[2] NBS, "China Statistical Data, National Bureau of Statistics," 2011.

http://219.235.129.58/reporView.do?Url=/xmlFiles/c62f1 433ec1a4160b0b3d208cc1a053b.xml\&id=c61f43b9a6f74 031a0ca60821 cb62fbf\&bgqDm=20094000

[3] W. G. Faix and A. Laier, "Soziale Kompetenz," 2nd Edition, Gabler, Wiesbaden, 1996. doi:10.1007/978-3-322-94543-3

[4] K.-L. Gutberlet and M. Knobloch, "Strategien, Methoden and Techniken der Internationalen Marktauswahl," In: K. Marcharzina and M.-J. Oesterle, Eds., Handbuch Internationales Management, 2nd Edition, Gabler, Wiesbaden, 2002, pp. 315-332.

[5] A. Picot, R. Reichwald and R. T. Wigand, "Die Grenzenlose Unternehmung," 5th Edition, Gabler, Wiesbaden, 2003.

[6] D. J. Devine, L. D. Clayton, J. L. Philips, B. B. Dunford and S. B. Melner, "Teams in Organizations. Prevalence, Characteristics, and Effectiveness," Small Group Research, Vol. 30, No. 6, 1999, pp. 678-711. doi: $10.1177 / 104649649903000602$

[7] B. D. Janz, J. A. Colquitt and R. A. Noe, "Knowledge Worker Team Effectiveness. The Role of Autonomy, Interdependence, Team Development, and Contextual Sup- port Variables," Personnel Psychology, Vol. 50, No. 4, 1997, pp. 877-904.

doi:10.1111/j.1744-6570.1997.tb01486.x

[8] R. A. Guzzo and M. W. Dickson, "Teams in Organizations: Recent Research on Performance and Effectiveness," Annual Review of Psychology, Vol. 47, No. 1, 1996, pp. 307-338. doi:10.1146/annurev.psych.47.1.307

[9] H. Arrow and J. E. McGrath, "Membership Dynamics in Groups at Work. A Theoretical Framework," Research in Organizational Behavior, Vol. 17, No. 1, 1995, pp. 373 411.

[10] D. R. Ilgen, J. R. Hollenbeck, M. Johnson and D. Jundt, "Teams in Organizations: From Input-Process-Output Models to IMOI Models," Annual Review of Psychology, Vol. 56, No. 1, 2005, pp. 517-543. doi:10.1146/annurev.psych.56.091103.070250

[11] J. Mathieu, M. T. Maynard, T. Rapp and L. Gilson, "Team Effectiveness 1997-2007: A Review of Recent Advancements and a Glimpse into the Future," Journal of Management, Vol. 34, No. 3, 2008, pp. 410-476. doi: $10.1177 / 0149206308316061$

[12] R. Helm, R. Meckl and N. Sodeik, "Systematisierung der Erfolgsfaktoren von Wissensmanagement auf Basis der Bisherigen Empirischen Forschung," Zeitschrift für Betriebswirtschaft, Vol. 77, No. 2, 2007, pp. 211-242. doi:10.1007/s11573-007-0017-4

[13] R. M. Hodgetts, F. Luthans and J. P. Doh, "International Management," 7th Edition, McGraw-Hill, New York, 2009.

[14] U. Schneider and C. Hirt, "Multikulturelles Management," München, Oldenbourg, Wien, 2007. doi: $10.1524 / 9783486592955$

[15] H. Guan, "Interkulturelles Management," Schriften zur Arbeits-, Betriebs- und Organisationspsychologie, Verlag Dr. Kovac, Hamburg, 2004.

[16] A. Podsiadlowski, "Interkulturelle Kommunikation and Zusammenarbeit," Vahlen, München, 2004.

[17] E. V. Keller, "Management in Fremden Kulturen. Ziele, Ergebnisse and Methodische Probleme der Kulturvergleichenden Managementforschung," Haupt, Bern, 1982.

[18] M. Hasenstab, "Interkulturelles Management: Bestandsaufnahme and Perspektiven," Verlag Wissenschaft \& Praxis, Sternenfels, 1999.

[19] J. Rothlauf, "Interkulturelles Management: Mit Beispielen aus Vietnam, China, Japan, Rußland und den Golfstaaten," 3rd Edition, Oldenbourg, München, 2009.

[20] J. Bolten, "Interkulturelle Kompetenz," Landeszentrale für Politische Bildung, Erfurt, 2001.

[21] H. H. Holzmüller, "Prozeduale Herausforderungen in der Forschung zum Interkulturellen Management und Ansätze zu deren Handhabung," In: M. Oesterle and S. Schmidt, Internationales Management: Forschung, Lehre, Praxis, Schäffer-Poeschel, Stuttgart, 2009, pp. 251-285.

[22] G. S. Yip, “Total Global Strategy II,” Prentice Hall, Englewood Cliffs, 2003.

[23] H. J. M. Hermans and H. J. G. Kempen, "Moving Cultures: The Perilous Problems of Cultural Dichotomies in a Globalizing Society," American Psychologist, Vol. 53, 
No. 10,1998 , pp. 1111-1120. doi:10.1037/0003-066X.53.10.1111

[24] R. Meckl, "Internationales Management," 2nd Edition, Franz Vahlen Verlag, München, 2010.

[25] C. K. Prahalad and G. Hamel, "The Core Competence of the Corporation," Harvard Business Review, Vol. 68, No. 3, 1990, pp. 79-91.

[26] T. Volery, "Ressourcenorientierter Ansatz von Entrepreneurship: Ressourcen sind der Kern des Wettbewerbsvorteils," KMU-Magazin, Vol. 9, No. 1, 2005, pp. 12-14.

[27] W. E. Watson, K. Kumar and L. K. Michaelsen, "Cultural Diversity's Impact on Interaction Process and Performance: Comparing Homogeneous and Diverse Task Groups," Academy of Management Journal, Vol. 36, No. 3, 1993, pp. 590-602. doi: 10.2307/256593

[28] C. Kirchmeyer and A. Cohen, "Multicultural Groups. Their Performance and Reactions with Constructive Conflict," Group \& Organization Management, Vol. 17, No. 2, 1992, pp. 153-170. doi:10.1177/1059601192172004

[29] T. H. Cox, S. A. Lobel and P. L. McLeod, "Effects of Ethnic Group Cultural Differences on Cooperative and Competitive Behavior on a Group Task," Academy of Management Journal, Vol. 34, No. 4, 1991, pp. 827-847. doi: $10.2307 / 256391$

[30] J. Turner, "Rediscovering the Social Group. A Social Categorization Theory," Blackwell, Oxford, 1987.

[31] H. Tajfel and J. C. Turner, "The Social Identity Theory of Intergroup Behavior," In: S. Worchel and W. G. Austin, Eds., Psychology of Intergroup Relations, Nelson, Chicago, 1986, pp. 7-24.

[32] D. Byrne, "The Attraction Paradigm," Academic Press, New York, 1971.

[33] M. Sherif and C. Sherif, "Social Psychology," Harper \& Raw, New York, 1969.

[34] M. Sherif, O. J. Harvey, B. J. White, W. R. Hood and C. W. Sherif, "Intergroup Conflict and Cooperation: The Robbers Cave Experiment," The University Book Exchange, Norman, 1961.

[35] A. Podsiadlowski, "Multikulturelle Arbeitsgruppen in Unternehmen: Bedingungen für Erfolgreiche Zusammenarbeit am Beispiel Deutscher Unternehmen in Südostasien," Waxmann, Münster, 2002.

[36] P. C. Earley and C. B. Gibson, "Multinational Work Teams: A New Perspective," Routledge, Mahwah, 2002.

[37] I. D. Steiner, "Group Process and Productivity," Academic Press, New York, 1972.

[38] M. L. Maznevski, "Understanding Our Differences: Performance in Decision-Making Groups with Diverse Members," Human Relations, Vol. 47, No. 5, 1994, pp. 531552. doi:10.1177/001872679404700504

[39] D. S. Canney and B. Z. Ekelund, "Effective Team Processes for Global Teams," In: H. Lane, M. Maznevski, M. Mendenhall and J. Mcnett, Eds., Handbook of Global Management, Blackwell Publishing, Malden, 2004, pp. 227-249.

[40] C. A. O'Reilly, D. F. Caldwell and W. P. Barnett, "Work
Group Demography, Social Integration, and Turnover,' Administrative Science Quarterly, Vol. 34, No. 1, 1989, pp. 21-37. doi:10.2307/2392984

[41] T. R. Zenger and B. S. Lawrence, "Organizational Demography: The Differential Effects of Age and Tenure on Technical Communication," Academy of Management Journal, Vol. 32, No. 2, 1989, pp. 353-376. doi: $10.2307 / 256366$

[42] T. H. Cox and S. Blake, "Managing Cultural Diversity: Implications for Organizational Competitiveness," Academy of Management Executive, Vol. 5, No. 3, 1991, pp. 45-56.

[43] T. Umans, "Research Angles on Cultural Diversity in Top Management Teams," Problems and Perspectives in Management, Vol. 7, No. 1, 2009, pp. 208-223.

[44] C. A. Bowers, J. A. Pharmer and E. Salas, "When Member Homogeneity Is Needed in Work Teams: A MetaAnalysis," Small Group Research, Vol. 31, No. 3, 2000, pp. 305-327. doi:10.1177/104649640003100303

[45] S. S. Webber and L. M. Donahue, "Impact of Highly and Less Job-Related Diversity on Work Group Cohesion and Performance: A Meta-Analysis," Journal of Management, Vol. 27, No. 2, 2001, pp. 141-162.

[46] G. Stewart, "A Meta-Analytic Review of Relationships between Team Design Features and Team Performance," Journal of Management, Vol. 32, No. 1, 2006, pp. 29-54. doi: $10.1177 / 0149206305277792$

[47] K. A. Jehn, "A Multimethod Examination of the Benefits and Detriments of Intragroup Conflict," Administrative Science Quarterly, Vol. 40, No. 2, 1995, pp. 256-282. doi: $10.2307 / 2393638$

[48] K. A. Jehn and E. Mannix, "The Dynamic Nature of Conflict: A Longitudinal Study of Intragroup Conflict and Group Performance," Academy of Management Journal, Vol. 44, No. 2, 2001, pp. 238-251. doi:10.2307/3069453

[49] K. W. Thomas, "Conflict and Conflict Management," In: M. D. Dunnette, Ed., Handbook of Industrial and Organizational Psychology, Rand McNally, New York, 1976, pp. 889-935.

[50] J. Hall, "Decisions, Decisions, Decisions," Psychology Today, Vol. 5, No. 1, 1971, pp. 51-54.

[51] G. Hofielen and J. Broome, "Leading International Teams: A New Discipline?" Zeitschrift für OrganisationsentWicklung, Vol. 20, No. 3, 2000, pp. 60-65.

[52] K. A. Jehn, "Affective and Cognitive Conflict in Work Groups: Increasing Performance through Value-Based Intragroup Conflict," In: C. K. W. De Dreu and E. Van de Vliert, Eds., Using Conflict in Organizations, Sage, London, 1997, pp. 87-100. doi:10.4135/9781446217016.n7

[53] C. K. W. de Dreu and L. R. Weingart, "Task versus Relationship Conflict, Team Performance, and Team Member Satisfaction: A Meta-Analysis," Journal of Applied Psychology, Vol. 88, No. 4, 2003, pp. 741-749. doi:10.1037/0021-9010.88.4.741

[54] M. Bruhn, "Unternehmens- und Marketingkommunikation," Vahlen, München, 2005.

[55] A. V. Matveev and P. E. Nelson, "Cross Cultural Communication Competence and Multicultural Team Perfor- 
mance: Perceptions of American and Russian Managers," International Journal of Cross Cultural Management, Vol. 42, No. 2, 2004, pp. 253-270. doi: $10.1177 / 1470595804044752$

[56] K. Lovelace, D. L. Shapiro and L. R. Weingart, "Maximizing Cross-Functional New Product Teams' Innovativeness and Constraint Adherence: A Conflict Communications Perspective," The Academy of Management Journal, Vol. 44, No. 4, 2001, pp. 779-793. doi: $10.2307 / 3069415$

[57] D. J. Kealey and D. R. Protheroe, "The Effectiveness of Cross-Cultural Training for Expatriates: An Assessment of the Literature on the Issue," International Journal of Intercultural Relations, Vol. 20, No. 2, 1996, pp. 141-165. doi:10.1016/0147-1767(96)00001-6

[58] P. Simon, "Die Entwicklung Eines Modells der Gruppeneffektivität und Eines Analyseinstruments zur Erfassung des Leistungspotentials von Arbeitsgruppen," Empirische Pädagogik e.V., Landau, 2002.

[59] B. Six and A. Eckes, "Der Zusammenhang von Arbeitszufriedenheit und Arbeitsleistung-Resultate Einer MetaAnalytischen Studie," In: L. Fischer, Ed., Arbeitszufriedenheit, Verlag für Angewandte Psychologie, Stuttgart, 1991, pp. 21-47.

[60] E. Elron, "Top Management Teams within Multinational Corporations: Effects of Cultural Heterogeneity," Leadership Quarterly, Vol. 8, No. 4, 1997, pp. 393-412. doi:10.1016/S1048-9843(97)90021-7

[61] K. G. Smith, K. A. Smith, J. D. Olian, H. P. Sims Jr., D. P. O'Bannon and J. A. Scully, "Top Management Team Demography and Process: The Role of Social Integration and Communication," Administrative Science Quarterly, Vol. 39, No. 3, 1994, pp. 412-438. doi:10.2307/2393297

[62] R. A. Guzzo and G. P. Shea, "Group Performance and Intergroup Relations in Organizations," In: M. D. Dunnette and L. M. Hough, Eds., Handbook of Industrial and Organizational Psychology, Consulting Psychologists Press, Palo Alto, 1992, pp. 269-313.

[63] O. Keiser, "Virtuelle Teams. Konzeptionelle Annäherung, Theoretische Grundlagen und Kritische Reflexion," Lang, Frankfurt (Main), 2002.

[64] C. E. Evans and K. L. Dion, "Group Cohesion and Performance," Small Group Research, Vol. 22, No. 1, 1991, pp. 175-186. doi:10.1177/1046496491222002

[65] B. Mullen and C. Cooper, "The Relation between Group Cohesiveness and Performance: An Integration," Psychological Bulletin, Vol. 115, No. 2, 1994, pp. 210-227. doi:10.1037/0033-2909.115.2.210

[66] T. M. Kühlmann, "Mitarbeiterführung in Internationalen Unternehmen," Kohlhammer, Stuttgart, 2008.

[67] R. J. House, P. J. Hanges, M. Javidan, P. W. Dorfman and V. Gupta, "Culture, Leadership, and Organizations," Sage, Thousand Oaks, 2004.

[68] H. Wendt, M. C. Euwema and I. J. H. van Emmerik, "Leadership and Team Cohesiveness across Cultures," The Leadership Quarterly, Vol. 20, No. 3, 2009, pp. 358370.

[69] M. J. Gelfand, D. P. S. Bhawuk, L. H. Nishii and D. J.
Bechtold, "Individualism and Collectivism," In: R. J. House, P. J. Hanges, M. Javidan, P. W. Dorfman and V. Gupta, Eds., Culture, Leadership, and Organizations, Sage, Thousand Oaks, 2004, pp. 437-512.

[70] W. Ling, R. C. Chia and L. Fang, "Chinese Implicit Leadership Theory," The Journal of Social Psychology, Vol. 140, No. 6, 2000, pp. 729-739. doi: $10.1080 / 00224540009600513$

[71] B. M. Bass, "Bass and Stogdill's Handbook of Leadership: Theory, Research, and Managerial Applications," 3rd Edition, Free Press, New York, 1990.

[72] B. M. Bass, "Leadership and Performance beyond Expectations," Free Press, New York, 1985.

[73] J. Felfe, "Transformationale und Charismatische FührungStand der Forschung und Aktuelle Entwicklungen," Zeitschrift für Personalpsychologie, Vol. 5, No. 4, 2006, pp. 163-176. doi:10.1026/1617-6391.5.4.163

[74] B. M. Bass and B. J. Avolio, "Improving Organizational Effectiveness through Transformational Leadership," Free Press, New York, 1994.

[75] D. Gebert, "Führung und Innovation," Kohlhammer, Stuttgart, 2002.

[76] K. P. Kuchinke, "Leadership and Culture: Work-Related Values and Leadership Styles among One Company's US and German Telecommunication Employees," Human Resource Development Quarterly, Vol. 10, 1999, pp. 135154. doi: $10.1002 /$ hrdq. 3920100205

[77] S. A. Wasti, "The Influence of Cultural Values on Antecedents of Organizational Commitment: An Individual Level Analysis," Applied Psychology: An International Review, Vol. 52, No. 4, 2003, pp. 533-554. doi:10.1111/1464-0597.00150

[78] J. Felfe, W. Yan and B. Six, "The Impact of Cultural Differences on Commitment and Its Influence on OCB, Turnover, and Strain," Paper Presented at the Annual Meeting of the Academy of Management, Atlanta, 2006.

[79] B. M. Bass and B. J. Avolio, "Multifactor Leadership Questionnaire," 3rd Edition, Mind Garden, Inc., Nebraska, 2004.

[80] B. Lieber, "Personalführung," Lucius und Lucius, Stuttgart, 2007.

[81] B. M. Bass, "Transformational Leadership: Industrial, Military, and Educational Impact," Erlbaum, New Jersey, 1998.

[82] S. P. Robbins, "Organisation der Unternehmung," 9th Edition, Pearson, München, 2001.

[83] H.-G. Ridder, "Personalwirtschaftslehre," 2nd Edition, Kohlhammer, Stuttgart, 2007.

[84] B. M. Bass and B. J. Avolio, "Manual for the Multifactor Leadership Questionnaire," Consulting Psychologists Press, Palo Alto, 1989.

[85] F. Lievens, P. van Geit and P. Coetsier, "Identification of Transformational Leadership Qualities: An Examination of Potential Biases," European Journal of Work and Organizational Psychology, Vol. 6, No. 4, 1997, pp. 415430. doi:10.1080/135943297399015

[86] M. L. Maznevski, J. J. DiStefano, C. B. Gomez, N. G. 
Noorderhaven and P. C. Wu, "Cultural Dimensions at the Individual Level of Analysis: The Cultural Orientations Framework," International Journal of Cross-Cultural Management, Vol. 2, No. 3, 2002, pp. 275-295. doi: $10.1177 / 147059580223001$

[87] F. R. Kluckhohn and F. L. Strodtbeck, "Variations in Value Orientations," 2nd Edition, Greenwood Press, Westport/ Connecticut, 1973.

[88] A. Bachmann and J. Wolf, "Führung Multikultureller Teams-Eine Konzeptualisierung und Empirische Analyse der Notwendigkeit Unterschiedlicher Führungsstile," Zeitschrift für Betriebswirtschaft, Vol. 77, No. 10, 2007, pp. 1035-1064. doi:10.1007/s11573-007-0319-6

[89] IMD, "Cultural Perspectives Questionnaire," 2009. http://www.imd.ch/research/projects/CPQ.cfm

[90] D. A. Harrison and K. J. Klein, "What's the Difference? Diversity Constructs as Separation, Variety or Disparity in Organizations," Academy of Management Review, Vol. 32, No. 4, 2007, pp. 1199-1228. doi:10.5465/AMR.2007.26586096

[91] K. A. Jehn and P. Shah, "Interpersonal Relationship and Task Performance: An Examination of Mediating Processes in Friendship and Acquaintance Groups," Journal of Personality and Social Psychology, Vol. 72, No. 4, 1997, pp. 775-790. doi:10.1037/0022-3514.72.4.775

[92] K. A. Jehn, "A Qualitative Analysis of Conflict Types and Dimensions in Organizational Groups," Administrative Science Quarterly, Vol. 42, No. 3, 1997b, pp. 530-557. doi: $10.2307 / 2393737$

[93] P. C. Earley and E. Mosakowski, "An Empirical Test of Transnational Team Functioning," Academy of Management Journal, Vol. 43, No. 1, 2000, pp. 26-49. doi: $10.2307 / 1556384$

[94] S. E. Seashore, "Group Cohesiveness in the Industrial Work Group," University of Michigan Press, Ann Arbor, 1954.

[95] G. van der Vegt and B. Emans, “Team Members' Affec- tive Responses to Patterns of Intragroup Interdependence and Job Complexity," Journal of Management, Vol. 26, No. 4, 2000, pp. 633-655.

[96] C. Vandenberghe, S. Stordeur and W. D'hoore, “Transactional and Transformational Leadership in Nursing: Structural Validity and Substantive Relationships," European Journal of Psychological Assessment, Vol. 18, No. 1, 2002, pp. 16-29. doi:10.1027//1015-5759.18.1.16

[97] M. Krafft, O. Götz and K. Liehr-Gobbers, "Die Validierung von Strukturgleichungsmodellen mit Hilfe des Partial-Least-Sqaures (PLS)-Ansatzes," In: F. Bliemel, A. Eggert, G. Fassot and J. Henseler, Eds., Handbuch PLSPfadmodellierung-Methode, Anwendung, Praxisbeispiele, Schäffer-Poeschel, Stuttgart, 2005, pp. 71-116.

[98] R. L. James, R. G. Demaree and G. Wolf, "Estimating within-Group Interrater Reliability with and without Response Bias," Journal of Applied Psychology, Vol. 69, No. 1, 1984, pp. 85-98. doi:10.1037/0021-9010.69.1.85

[99] W. P. Dunlap, M. J. Burke and K. Smith-Crowe, “Accurate Tests of Statistical Significance for rwg and Average Deviation Interrater Agreement Indexes," Journal of Applied Psychology, Vol. 88, No. 2, 2003, pp. 356-362. doi:10.1037/0021-9010.88.2.356

[100] J. M. LeBreton and J. L. Senter, “Answers to 20 Questions about Interrater Reliability and Interrater Agreement," Organizational Research Methods, Vol. 11, No. 4, 2008, pp. 815-852.

[101] R. Weiber and D. Mühlhaus, "Strukturgleichungsmodellierung," Springer, Berlin/Heidelberg, 2010.

[102] C. Fornell and J. Cha, "Partial Least Squares," In: R. Bagozzi, Ed., Advanced Methods of Marketing Research, Blackwell, Cambridge, 1994, pp. 52-87.

[103] G. K. Stahl, K. Mäkelä, L. Zander and M. L. Maznevski, "A Look at the Bright Side of Multicultural Team Diversity," Scandinavian Journal of Management, Vol. 26, No. 4, 2010, pp. 439-447. doi:10.1016/j.scaman.2010.09.009 